\title{
$\$$ Research Square

\section{Integrating ART Adherence Support Technologies in the Care of Pregnant and Postpartum Women With HIV: A Qualitative Study}

Sara Rendell ( $\sim$ srendell@pennmedicine.upenn.edu )

University of Pennsylvania Perelman School of Medicine https://orcid.org/0000-0002-8201-4793

Harald Schmidt

Leonard Davis Institute of Health Economics

Rebecca Neergaard

: University of Pennsylvania Department of Family Medicine and Community Health

Hervette Nkwihoreze

University of Pennsylvania Department of Medicine

\section{Zoe Barbati}

University of Pennsylvania Department of Family Medicine and Community Health

William R. Short

University of Pennsylvania Department of Medicine

\section{Aadia I. Rana}

UAB DOM: The University of Alabama at Birmingham Department of Medicine

Anandi N. Sheth

Emory University Department of Medicine

Rachel K. Scott

MedStar Health Research Institute

Sonia Sethi

Rush University Medical Center

Florence M. Momplaisir

University of Pennsylvania Department of Medicine

\section{Research}

Keywords: Adherence, HIV care continuum, Pregnancy, Postpartum Period, Anti-Retroviral Agents (ARV), Implementation science

Posted Date: February 15th, 2022

DOI: https://doi.org/10.21203/rs.3.rs-1303784/v1 
License: (c) (i) This work is licensed under a Creative Commons Attribution 4.0 International License. Read Full License 


\section{Abstract}

Background: We have a limited understanding on how to best integrate technologies to support antiretroviral therapy (ART) adherence in routine HIV care.

Methods: We conducted semi-structured interviews with multidisciplinary providers caring for pregnant and postpartum women with HIV and asked providers about their perspectives on utilising adherence support technologies such as text messages, video check-ins with providers or automated with facial recognition for directly-observed-therapy, signaling pill bottle, and signaling pill to support ART adherence. Each approach generated an adherence report. The interview instrument was guided by the Consolidated Framework for Implementation Research and included questions on the implementation climate, barriers and facilitators to the clinical integration of the adherence approach and strategies that could be used to maximize this integration. The order of adherence support technologies was randomized to minimize bias. We used a modified grounded theory to develop the coding structure and two coders applied the codebook to the transcripts after establishing strong inter-rater reliability with $20 \%$ of interviews (kappa = $0.82)$.

Results: Between March and December 2020, we conducted 26 in-depth, semi-structured interviews with providers who weighed several factors when considering each approach, including the approach's effect on patient-provider interaction in and outside of the clinic visit, timing for and duration of the approach's utility, threat of disclosing status, and added burden to providers (e.g., needing to act on generated information) or to patients (e.g., needing to hide the signaling pills, responding to text messages). Providers' most preferred approach was text-messages, and the least preferred was the signaling pill. Barriers to acceptability varied by approach and included perceived surveillance, violation of privacy, added time demand for providers, potential inaccuracy of the adherence data generated, and negative impact on the patient-provider relationship, particularly if the approach was perceived as coercive. Payers anticipated regulatory hurdles with unfamiliar approaches, particularly the signaling pill and signaling pill bottle. Facilitators included strengthened therapeutic alliance, predictable reminder mechanisms, and options for customization according to patient preference.

Conclusions: Our study elucidates barriers and facilitators to integrating technology-based adherence support approaches in clinical care to support adherence of pregnant and postpartum women with HIV.

\section{Contributions To The Literature}

- Health care providers' perspectives are crucial to inform the successful implementation of evidencebased approaches. Technology-based approaches that support adherence to antiretroviral therapy (ART) offer objective measures of ART adherence during pregnancy and the postpartum period, when many women experience HIV treatment interruption.

- Providers identified numerous barriers, including the threat of compromising the patient-provider relationship, and facilitators, including accessibility to patients and opportunities for more contact 
with the multidisciplinary team.

- These findings reveal barriers and facilitators of each approach and clarify how, when, and why providers might utilize each approach to improve the care of pregnant and postpartum women with HIV.

\section{Background}

Antiretroviral therapy (ART) is an evidence-based practice that halts progression of maternal HIV and reduces the risk of perinatal transmission. Adherence is often suboptimal, especially in the postpartum period, and currently interventions aiming at supporting ART adherence for women with HIV in the perinatal period are lacking [1]. Technology-based adherence support approaches are attractive because they use automated mechanisms to increase accuracy of adherence patterns and thus, can facilitate provider-patient discussions around ART adherence. In addition, they can be combined with other effective strategies, including peer support and case management, to identify and address barriers to ART adherence. Examples of technology-based adherence support approaches include text message reminders, video calls with providers, automated video check-ins, electronic pill bottles that send signals when containers are opened, and pills with embedded sensors [2-6]. Barriers and facilitators to their integration in clinical care have not been well described and are needed to enable provider teams to support patients struggling with ART adherence. We used the Consolidated Framework for Implementation Research (CFIR) to elucidate perspectives of HIV providers and information about how each approach is situated within existing workflows and systems [7-8], that can inform the implementation of adherence support approaches in clinical practice. Within the CFIR, key domains include: 1) intervention characteristics (i.e., characteristics of each adherence support approach); (2) outer setting (i.e., the economic, political, and social context within which an organization exists); (3) inner setting (i.e., the structural and cultural climate through which an implementation process proceeds); (4) characteristics of staff involved in implementation; and (5) the implementation process [7].

Provider perspectives are crucial to the successful implementation of adherence support approaches as provider buy-in is needed for the successful uptake of these approaches [9-10]. To date, few studies have elicited the attitudes of providers who care for pregnant or postpartum women with HIV regarding technology-based adherence approaches, even though these providers decide about the implementation of various adherence supports for their patients [12-14]. The current study aimed to address this gap in the literature and reduce the gap between research and practice by weighting the pros and cons of each approach and discussing ways in which these approaches can be integrated in clinical care.

\section{Methods}

We conducted semi-structured interviews with multi-disciplinary providers as part of an ongoing multi-site study testing a peer-led behavioral intervention to improve adherence and retention in care for pregnant and postpartum women with HIV (15). They included members of a comprehensive care team providing obstetric and HIV care and services to this patient population (advanced practice providers (APP), 
registered nurses (RN), perinatal case managers and HIV-specialized physicians, including OB/GYNs). For this study, the term "providers" refers to the range of healthcare professionals providing care and services to pregnant/postpartum women with HIV, not only physicians. In keeping with CFIR which considers a diversity of perspectives for the implementation of interventions, we also interviewed health payers (insurers) with a senior role in benefit design (patient interviews are ongoing as of this writing). Study sites were in four cities with high HIV infection prevalence: Philadelphia, PA, Washington DC, Atlanta, GA and Birmingham, AL. We recruited providers from clinics funded by the Health Resources and Services Administration's Ryan White Comprehensive AIDS Resources Emergency Act.

The University of Pennsylvania Institutional Review Board approved the study (protocol number: 842757), and written informed consent was obtained from all study participants. To avoid conflicts with clinical responsibilities, interviews were scheduled according to each participant's availability over a ten-month period, from March through December of 2020.

\section{Recruitment}

We identified providers and payers through purposive sampling to target a variety of perspectives at each site. Clinical directors identified most experienced staff members who were then invited to participate in the study by a research specialist from the Mixed Methods Research Lab (MMRL) at the University of Pennsylvania. Participants were also asked to recommend colleagues of good fit for the project, who were then contacted for an interview. Recruitment stopped after we met target numbers for each category (physician, APP, RN, case manager, and payer) and if saturation of themes based on barriers and facilitators mentioned across each approach was met, with a goal of a minimum of 25 provider interviews.

\section{Study Instrument}

The study collaborators designed a survey instrument in collaboration with an MMRL specialist drawing on the CFIR [7-8] and the Structural Vulnerability Assessment Tool which elucidates the pathways through which specific local hierarchies and broader sets of power relationships influence health [16]. Specialists in instrument design, interviewing, and qualitative analysis at the MMRL then piloted the survey instrument with participants and made minor adjustments to the instrument based on relevance and clarity of each question. The final interview instrument included 36 questions grouped into several themes relevant to the implementation climate including: narratives for non-adherence, perceptions about monitoring and tracking adherence, barriers and facilitators regarding the five adherence support approaches (namely, text message reminders, video check-ins with providers for directly observed therapy, automated video check-in with facial and pill recognition for directly observed therapy, a signaling pill bottle, or a signaling pill), accompanied by a one-page visualization of each support approach (Table 1). Each approach was paired with adherence record keeping, done automatically or manually based on the approach. 
Table 1

Adherence Support Approaches

\section{Adherence Description Approach}

Signaling Smartphone app reminds patients when it is time to take their pill. Each pill is fitted Pill with a sensor and when it reaches the stomach, the sensor sends a signal to a computer system. The computer system records whether and when the pill was taken, and adherence records can be automatically shared with others.

Signaling

Pill Bottle
Pill bottle flashes light when it is time for the patient to take their pill. When the cap is removed, the pill bottle lid automatically sends a message to a computer system. The computer system records whether and when a pill bottle was opened, and adherence records can be automatically shared with others.

Video A provider calls and observes patient taking their pill via smartphone or computer, Check with Provider using a video platform such as FaceTime or Skype. The provider records whether and when a pill was taken, and adherence records can be manually shared with others.

Automated A computer program with facial and pill recognition ability calls the patient on their Video Check smartphone or computer. The computer program watches the patient take their pill and records whether and when a pill was taken. Adherence records can be automatically shared with others.

Text Messages
Provider reminds patient it is time to take their pill via text message. The patient takes their pill and responds, reporting whether and when they took their medication. Adherence records can be shared with others. 
Table 2

Interview Participant Characteristics

\begin{tabular}{|c|c|c|}
\hline Role & Number & Percentage \\
\hline Physician & 8 & $30.8 \%$ \\
\hline Nurse Practitioner & 1 & $3.8 \%$ \\
\hline Nurse & $4^{\dagger}$ & $15.4 \%$ \\
\hline Case Manager & 10 & $38.5 \%$ \\
\hline Insurer (Payer) & $3^{\dagger}$ & $11.5 \%$ \\
\hline Total & 26 & \\
\hline Years of experience in HIV care & Number & Percentage \\
\hline $0-5$ & 5 & $21.7 \%$ \\
\hline 6-10 & 4 & $17.4 \%$ \\
\hline 11 or more & 14 & $60.9 \%$ \\
\hline Total & $23^{+}$ & \\
\hline Experience in Ryan White clinics (years) & Number & Percentage \\
\hline $0-5$ & 4 & $17.4 \%$ \\
\hline $6-10$ & 6 & $26.1 \%$ \\
\hline 11 or more & 10 & $43.5 \%$ \\
\hline NA & 3 & $13.0 \%$ \\
\hline Total & $23^{+}$ & \\
\hline Experience with peripartum women (years) & Number & Percentage \\
\hline 0-5 & 6 & $26.1 \%$ \\
\hline $6-10$ & 6 & $26.1 \%$ \\
\hline 11 or more & 10 & $43.5 \%$ \\
\hline NA & 1 & $4.3 \%$ \\
\hline Total & $23^{+}$ & \\
\hline Self-identified Gender & Number & Percentage \\
\hline Male & 2 & $8.7 \%$ \\
\hline Female & 20 & $86.9 \%$ \\
\hline
\end{tabular}




\begin{tabular}{|c|c|c|}
\hline Other & 1 & $4.3 \%$ \\
\hline Total & $23^{\dagger}$ & \\
\hline Self-Identified Race/Ethnicity & Number & Percentage \\
\hline Asian & 2 & $8.7 \%$ \\
\hline Black or African American & 8 & $34.8 \%$ \\
\hline Hispanic or Latinx & 1 & $4.3 \%$ \\
\hline White & 11 & $47.8 \%$ \\
\hline NA & 1 & $4.3 \%$ \\
\hline Total & $23^{+}$ & \\
\hline Age & Number & Percentage \\
\hline $20-39$ & 7 & $30.4 \%$ \\
\hline $40-59$ & 13 & $56.5 \%$ \\
\hline $60+$ & 2 & $8.7 \%$ \\
\hline NA & 1 & $4.3 \%$ \\
\hline Total & $23^{\dagger}$ & \\
\hline
\end{tabular}

The order in which approaches were presented and providers were asked about these approaches was randomized to minimize inadvertently influencing the conversation in favor of or against an approach. We left it to providers to determine the hypothetical frequency of use for each approach based on their clinic's capacity to enable further characterization of the implementation climate. After completing interviews, providers were invited to participate in a brief demographic survey.

\section{Data Analysis}

NVivo 12 Plus was used for coding of interview transcripts [17]. Using a modified grounded theory for content analysis, we developed a codebook to closely match common themes identified in the interviews. Study team members reviewed and discussed the codebook at coding meetings and refined it using an iterative process, that included coding to question, theme generation, and subsequent coding to theme. Two coders from the MMRL then applied the resulting codebook and established strong inter-rater reliability with $20 \%$ of interviews (kappa $=0.82$ ). The remaining interviews were divided between reviewers and coded independently. A table summarizing provider perspectives (Table 3 ) was generated 
from coded interviews by identifying where codes for each adherence support measure overlapped with reflections on them, including manual counts of frequency of appearance of each idea in interview transcripts. 
Table 3

Overview of Provider Perceptions of Adherence Support Approaches

\begin{tabular}{|c|c|c|c|c|c|}
\hline & $\begin{array}{l}\text { Effect on } \\
\text { Patient- } \\
\text { Provider } \\
\text { Relationship }\end{array}$ & $\begin{array}{l}\text { Effect on } \\
\text { Provider } \\
\text { Workflow }\end{array}$ & $\begin{array}{l}\text { Threat of Status } \\
\text { Disclosure }\end{array}$ & $\begin{array}{l}\text { Access and } \\
\text { Ability }\end{array}$ & $\begin{array}{l}\text { Suggestions } \\
\text { for } \\
\text { Customization }\end{array}$ \\
\hline $\begin{array}{l}\text { Text } \\
\text { Message }\end{array}$ & $\begin{array}{l}\text { Facilitator: } \\
\text { patient can } \\
\text { form a } \\
\text { relationship } \\
\text { with provider } \\
\text { they text with } \\
(1)^{\ddagger} \\
\text { Barrier: fear of } \\
\text { becoming a } \\
\text { nuisance to } \\
\text { patients after } \\
\text { repeated } \\
\text { messages (1) }\end{array}$ & $\begin{array}{l}\text { Facilitator: } \\
\text { can } \\
\text { automate (1) } \\
\text { and gives } \\
\text { providers } \\
\text { access to } \\
\text { adherence } \\
\text { data (1) } \\
\text { Barrier: } \\
\text { burdens } \\
\text { providers to } \\
\text { text many } \\
\text { patients at all } \\
\text { hours (5) }\end{array}$ & $\begin{array}{l}\text { Facilitator: } \\
\text { offers more } \\
\text { privacy than call } \\
\text { options (2) } \\
\text { Barrier: risk of } \\
\text { disclosure for } \\
\text { patients with } \\
\text { friends/family } \\
\text { who have } \\
\text { access to their } \\
\text { phone (4) }\end{array}$ & $\begin{array}{l}\text { Facilitator: } \\
\text { the majority } \\
\text { of patients } \\
\text { have the } \\
\text { ability to text } \\
\text { (9) } \\
\text { Barrier: some } \\
\text { patients lack } \\
\text { a phone or } \\
\text { have limited } \\
\text { texting } \\
\text { ability (2) }\end{array}$ & $\begin{array}{l}\text { Personalize } \\
\text { the text } \\
\text { message (2) } \\
\text { Combine with } \\
\text { the signaling } \\
\text { pill box (1) } \\
\text { Use to help } \\
\text { patients start } \\
\text { a routine and } \\
\text { then stop (3) }\end{array}$ \\
\hline $\begin{array}{l}\text { Video } \\
\text { Check with } \\
\text { Provider }\end{array}$ & $\begin{array}{l}\text { Facilitator: } \\
\text { gives the } \\
\text { patient the } \\
\text { chance to } \\
\text { develop a } \\
\text { close } \\
\text { relationship } \\
\text { with } \\
\text { provider(12) } \\
\text { Barrier: patient } \\
\text { may feel } \\
\text { uncomfortable } \\
\text { being watched } \\
(1)\end{array}$ & $\begin{array}{l}\text { Facilitator: } \\
\text { NA } \\
\text { Barrier: a lot } \\
\text { of work for } \\
\text { provider to } \\
\text { call all } \\
\text { patients } \\
\text { every day to } \\
\text { watch them } \\
\text { take their } \\
\text { pills (9) }\end{array}$ & $\begin{array}{l}\text { Facilitator: NA } \\
\text { Barrier: may } \\
\text { create problems } \\
\text { if patient is } \\
\text { around others } \\
\text { who are not } \\
\text { aware of HIV } \\
\text { status at time of } \\
\text { video call (5) }\end{array}$ & $\begin{array}{l}\text { Facilitator: } \\
\text { NA } \\
\text { Barrier: } \\
\text { patient } \\
\text { needs to } \\
\text { have and } \\
\text { understand } \\
\text { the } \\
\text { technology } \\
\text { necessary } \\
\text { for video } \\
\text { calls (4) }\end{array}$ & $\begin{array}{l}\text { Valuable at } \\
\text { particular } \\
\text { times in } \\
\text { pregnancy (2) } \\
\text { Use this for } \\
\text { limited period } \\
\text { while patient } \\
\text { is developing } \\
\text { a routine (3) } \\
\text { Assure the } \\
\text { person calling } \\
\text { has a } \\
\text { relationship } \\
\text { with the } \\
\text { patient (1) } \\
\text { Train patients } \\
\text { to use the } \\
\text { technology (1) }\end{array}$ \\
\hline
\end{tabular}




\begin{tabular}{|c|c|c|c|c|c|}
\hline & $\begin{array}{l}\text { Effect on } \\
\text { Patient- } \\
\text { Provider } \\
\text { Relationship }\end{array}$ & $\begin{array}{l}\text { Effect on } \\
\text { Provider } \\
\text { Workflow }\end{array}$ & $\begin{array}{l}\text { Threat of Status } \\
\text { Disclosure }\end{array}$ & $\begin{array}{l}\text { Access and } \\
\text { Ability }\end{array}$ & $\begin{array}{l}\text { Suggestions } \\
\text { for } \\
\text { Customization }\end{array}$ \\
\hline $\begin{array}{l}\text { Automated } \\
\text { Video } \\
\text { Check }\end{array}$ & $\begin{array}{l}\text { Facilitator: NA } \\
\text { Barrier: lack of } \\
\text { opportunity to } \\
\text { connect with } \\
\text { provider (4) }\end{array}$ & $\begin{array}{l}\text { Facilitator: } \\
\text { requires less } \\
\text { labor and } \\
\text { money, but } \\
\text { gives the } \\
\text { same } \\
\text { amount of } \\
\text { adherence } \\
\text { data (7) } \\
\text { Barrier: NA }\end{array}$ & $\begin{array}{l}\text { Facilitator: NA } \\
\text { Barrier: may } \\
\text { create problems } \\
\text { if patient is } \\
\text { around others } \\
\text { who are not } \\
\text { aware of HIV } \\
\text { status at time of } \\
\text { video call (1) }\end{array}$ & $\begin{array}{l}\text { Facilitator: } \\
\text { NA } \\
\text { Barrier: } \\
\text { patient } \\
\text { needs to } \\
\text { have and } \\
\text { understand } \\
\text { technology } \\
\text { necessary } \\
\text { for video } \\
\text { calls (4) }\end{array}$ & $\begin{array}{l}\text { Tailor } \\
\text { interaction to } \\
\text { the patient } \\
\text { and change it } \\
\text { regularly to } \\
\text { retain } \\
\text { engagement } \\
\text { (1) } \\
\text { Calls start } \\
\text { with a } \\
\text { provider and } \\
\text { transition to } \\
\text { automated } \\
\text { over time (1) }\end{array}$ \\
\hline $\begin{array}{l}\text { Signaling } \\
\text { Pill Bottle }\end{array}$ & $\begin{array}{l}\text { Facilitator: } \\
\text { patient can be } \\
\text { proud to show } \\
\text { adherence } \\
\text { record to } \\
\text { provider (1) } \\
\text { Barrier: } \\
\text { signaling } \\
\text { distrust by } \\
\text { tracking } \\
\text { adherence (1) }\end{array}$ & $\begin{array}{l}\text { Facilitator: } \\
\text { little work for } \\
\text { providers to } \\
\text { do with this } \\
\text { intervention } \\
\text { (2) } \\
\text { Barrier: } \\
\text { someone } \\
\text { needs to } \\
\text { organize data } \\
\text { (1) }\end{array}$ & $\begin{array}{l}\text { Facilitator: NA } \\
\text { Barrier: flashing } \\
\text { light can attract } \\
\text { unwanted } \\
\text { attention to } \\
\text { medication (9) }\end{array}$ & $\begin{array}{l}\text { Facilitator: } \\
\text { method of } \\
\text { getting and } \\
\text { taking pills } \\
\text { does not } \\
\text { change (1) } \\
\text { Barrier: NA }\end{array}$ & $\begin{array}{l}\text { Have } \\
\text { someone call } \\
\text { the patient if } \\
\text { pill cap isn't } \\
\text { opened (2) } \\
\text { Have a } \\
\text { second } \\
\text { reminder if pill } \\
\text { cap isn't } \\
\text { opened (1) } \\
\text { Send a text } \\
\text { message } \\
\text { along with the } \\
\text { reminder light } \\
\text { (2) }\end{array}$ \\
\hline $\begin{array}{l}\text { Signaling } \\
\text { Pill }\end{array}$ & $\begin{array}{l}\text { Facilitator: } \\
\text { patient gets } \\
\text { additional } \\
\text { support } \\
\text { without } \\
\text { having to } \\
\text { reach out for it } \\
\text { (1) } \\
\text { Barrier: } \\
\text { signaling } \\
\text { distrust by } \\
\text { tracking } \\
\text { adherence (2) }\end{array}$ & $\begin{array}{l}\text { Facilitator: } \\
\text { tech does the } \\
\text { work of } \\
\text { checking up } \\
\text { on patients } \\
\text { for the } \\
\text { provider (2) } \\
\text { Barrier: } \\
\text { someone } \\
\text { needs to } \\
\text { monitor } \\
\text { adherence } \\
\text { data (1) }\end{array}$ & $\begin{array}{l}\text { Facilitator: NA } \\
\text { Barrier: concerns } \\
\text { about using } \\
\text { tracking device } \\
\text { being tied to HIV } \\
\text { status (2) }\end{array}$ & $\begin{array}{l}\text { Facilitator: } \\
\text { NA } \\
\text { Barrier: need } \\
\text { a smart } \\
\text { phone and } \\
\text { comfort with } \\
\text { technology } \\
\text { of } \\
\text { intervention } \\
\text { (2) }\end{array}$ & $\begin{array}{l}\text { Only useful } \\
\text { for a short } \\
\text { period of time } \\
\text { (1) }\end{array}$ \\
\hline
\end{tabular}




\section{Results}

Provider characteristics are presented in Table 2. Providers were primarily female (87\%), and from diverse disciplines a majority of whom $(78.3 \%)$ had six or more years of experience in HIV care.

\section{Inner Setting for Adherence Support Approaches}

Providers weighed the effect of a particular approach on patient-provider interactions in and outside of the clinic visit and the possible added burden to providers or clinic staff, including having to act on information once it was known. Providers also thought that added burdens could extend to patients; for example, patients might need to store the signaling pills in a new location as the signal emitted might attract unwanted attention for individuals who have not disclosed their status. Patients might also feel that they are expected to respond to text messages. Several providers described that having a low number of patients who are pregnant or postpartum, compared to the larger clinic volume, could serve as a facilitator to the integration of a new technology for this population, by reducing the overall time burden required to respond to output. Others remarked that the data provided by these approaches could easily be integrated on an existing electronic health record (EHR) and to other EHR-based initiatives they had adopted to assess practice-wide adherence metrics. Providers across sites consistently described human effort and burden (time and tasks) as key factors they would weigh in when considering which adherence support approach to select.

\section{Outer Setting for Adherence Support Approaches}

Providers situated adherence among many challenges their patients navigate, including housing instability, food insecurity, and legal difficulties. "I have not found adherence itself to be the major problem, but more the steps before it. [...]" (Physician). One payer with prior experience as a HIV physician described housing as the "fifth vital sign." Discrimination and hardship based on race, immigration status, and socioeconomic status were cited as consistent contributors to nonadherence. Payers understood adherence as subject to rapid changes: "Somebody can be completely $100 \%$ adherent for six months and then things can happen in their lives that drop off"(Payer). Case managers observed that adherence declines when patients lack the basic security of stable shelter, and ability to pay bills and feed oneself and one's family: "It's usually not a medication access thing. It's, 'Oh, I take the medication, and I need to eat with it, but I didn't have any food, so I missed the med because I didn't have any food"' (Case Manager). For providers, connection to care was inextricable from medication adherence. Actions taken to identify and ameliorate the upstream, outer context causes for non-adherence were understood by providers to be intrinsic to, rather than separate from, their clinical responsibilities. Providers tended to view "human connection" as integral to identifying such factors and to developing collaborative plans to address them. Providers consistently identified the postpartum period as particularly challenging for retention in care and ART adherence, citing comparatively fewer resources available than during pregnancy, as one physician put it, "there is loss of insurance, pregnancy [coverage], and sometimes their source of payment for the medication changes." Dominant external setting themes in provider explanations for declining adherence postpartum included increased financial, cognitive and physical 
demands in the setting of sometimes loosing access to financial supports available during pregnancy; direct competition between care for self and care for newborn; declining risk of avoiding perinatal transmission; and postpartum depression. Providers did not view technology-based approaches as a solution to addressing social determinants but as one of many tools that could be used to better support women's ART adherence in the postpartum period.

\section{Intervention Characteristics and Implementation Process}

Providers explicitly prioritized approaches that they felt would enhance patients' overall wellness and promote patient-provider trust. Text messaging was the most popular approach because it was familiar to providers, easily accessible to patients, and could enhance patient-provider relationships. The text message approach was also perceived as less invasive compared with other approaches. There were greater concerns about privacy and surveillance for the signaling pill, signaling pill bottle, video check with provider, and automated video check. Table 3 provides an overview of associations providers made between adherence support approaches and factors they deemed important. The most consistently cited facilitators were enhancing patient-provider relationship, predictable reminder mechanisms, and options for customization based on patient preference. Payers anticipated regulatory hurdles with unfamiliar approaches, particularly the signaling pill and signaling pill bottle. Below, we discuss barriers and facilitators to each approach in detail and strategies that can be used to integrate use of the approach in clinical care.

\section{Text Messages}

Providers saw text reminders as an opportunity to develop better and more frequent interactions with patients. They believed text message reminders and report could be helpful for most patients, as most have text-capable devices, check them frequently, and know how to text. Providers presumed younger patients would text more often and more seamlessly utilize the intervention. Many providers had successfully used text messages to contact their patients in the past.

Barriers included the ease of ignoring a text message or responding dishonestly which were seen as a diminishing return for investment. The frequency of text messages was also concern. One physician shared, "my general experience is that after two-to-four weeks, they began to ignore [text reminders]. You never want to get to that place that the patient is now avoiding the interaction." Providers expressed concerns about HIV status disclosure through a text message, especially if a patient shared a phone. Several case managers described how even a discrete message could become "a potential outing for that patient" (Case Manager). Providers suggested that customizing reminder texts could resolve issues around disclosure, potentially facilitating use of the approach.

\section{Video Check with Providers}

Facilitators to this approach included a sense that video checks could improve the therapeutic alliance, as a "social approach" seen to enable "human connection", a factor thought to mitigate outer context barriers providers emphasized. Providers framed the video check as best for patients who enjoy person- 
to-person contact. Providers suggested newly diagnosed patients, patients switching medications, and postpartum women for this approach. Overall, providers conceptualized video calls as a temporary tool for establishing or strengthening an adherence routine.

Barriers to this intervention included high demand on providers, requirement of video-calling capable devices, and the possibility of becoming cumbersome to patients: "It would take a lot of time and a lot of resources to make sure that patients have access to a smartphone and can Skype or FaceTime" (Case Manager). Providers feared a video call would make patients feel invaded: "With our population with the stigma and all of it, I don't think that'll work because [if] somebody is watching [a patient take a pill], the [patient] probably will feel violated" (Case Manager).

\section{Automated Video Check}

Providers were less enthusiastic about the automated video check, and few thought it would appeal to patients. Barriers included perceiving this option as a less personalized approach and one whose facial recognition technology risked patient discomfort. Generally, providers felt the automated call incurred the same effort of a live video call without the benefits of human connection with a provider.

"This method doesn't offer any of the support that the video potentially could. The video that we usually do is like a quick check in. "How are you feeling? Are you ready to take your pills today? Great, let's take it. Oh, you did such a good job." There's a positive reinforcement as opposed to a video just recording." (Physician)

However, some thought it might help non-adherent patients who found personal contact burdensome. Providers viewed the automated video call as less resource-intensive for providers and less intrusive for patients and saw it as a possible method for stepping down from personal contacts.

\section{Signaling Pill Bottle}

Facilitators to this approach included an appreciation of the novelty of this visual reminder (e.g., remarking that a blinking pill bottle was an unheard of and exciting way to help patients remember whether they had taken their medications on a given day) and a sense that it would not disrupt routines for picking up and taking pills, even though it could change how patients store pills.

However, providers remarked that flashing pill bottles are not discreet for those trying to keep their status private who, for example, conceal their pills in a vitamin bottle. "Anything that would draw attention to the medication would be something they would want to avoid" (Physician). In addition to disclosure concerns, providers noted that the signaling pill bottle could be ineffective for patients who do not store their pills in the original prescription bottle or in a visible location (for example, keeping pills in a pill organizer or drawer). One physician worried the signaling bottle could communicate an "assumption that you don't trust the patient being able to take their meds without being monitored." The most common concern among providers was that the data from the signaling pill bottle could be misleading if a patient opened the bottle but did not take their pill. 


\section{Signaling Pill}

Many providers thought patients would dislike swallowing a sensor due to feelings of being watched or having their privacy invaded. Additionally, some providers worried that relying on the signaling pill rather than patient report to assess adherence could threaten the patient-provider relationship. "In some ways, it's signaling a lack of trust to the patient" (Case Manager). Providers believed the signaling pill would be ideal for patients who were chronically non-adherent and dishonest in reporting missed pills, though they speculated those patients would not accept the approach. Facilitators included an appreciation of the accuracy of information from the signaling pill, even if few expressed willingness to use it.

\section{Mixed reactions to detailed record keeping on medication adherence}

Overall, providers differentiated supporting from verifying adherence, despite the potential for each approach to combine both functions. When asked whether they would like a detailed report of whether and when their patients take their medications, providers offered mixed responses. A plurality of providers $(\mathrm{N}=12 / 26)$ speculated that information would be "a nice tool" or could enable them to locate specific causes for missed doses. One provider felt positively about this option but added, "I'd definitely question how that information is collected and the validity and the [re]liability[...]" (RN). Others thought a detailed report would contribute little to their preexisting clinical practice. Overall, providers emphasized that having data does not lead directly to having the resources and capacity to address the problem(s) the data reveal.

\section{Discussion}

Provider perspectives on implementation of adherence support technologies for pregnant and postpartum women with HIV included an explicit focus on how to best care for each patient, noting heterogeneity in social, economic, and structural vulnerabilities, that could influence adoption of each approach. While providers perceived opportunities for each of the approaches, they consistently expressed concern about possible detrimental effects: the most frequently cited barrier was the threat of compromising the patient-provider relationship and the most consistently mentioned facilitators were perceived accessibility to patients and the opportunity to forge more contact with the multidisciplinary team. Provider effort and added burdens on patients, and care team members were strong considerations informing the feasibility of integrating each approach within clinical care. Past experiences with the approach positively influenced acceptability to providers, which partially explains why text messaging was the preferred approach. Additionally, familiarity with an analogous approach positively influenced feasibility as providers considered scenarios by which the data generated could be integrated in the EHR. These results indicate that adherence support approaches can be effective tools to enhance ART adherence if they are customized to the needs of patients; adapted to clinic resources, and strategies to address barriers to their integration in clinical care are used. 
In our study, providers emphasized outer setting factors influencing adherence, including housing instability and discrimination. Such an emphasis is consistent with scientific evidence that has established the significant influence of such factors on women's HIV self-management [18-20]. Automated systems cannot address structural barriers by themselves but do present opportunities for task-shifting which could free time providers spend on adherence assessment during patient encounters to be instead devoted to addressing barriers to ART adherence [21]. However, in the current study, providers tended to more frequently anticipate that these approaches would increase workload, unless the approach was integrated with an existing data management system or adapted to address patient preferences, including frequency of contact and preservation of privacy. One recent study assessing provider perceptions of a mobile messaging intervention designed to encourage patients to remain in care found that health care providers tended to balance considerations of practicality and added workload with potential to improve patient-provider relations and weighed the latter more heavily [21]. Provider weighting was again consistent with scientific evidence revealing that positive relationships with providers and clinic staff facilitate retention in care for patients with HIV [22].

Our study has several limitations. Because it is descriptive in nature, it does not establish causal associations or describe the relative likelihood of providers to using a specific approach. Though the order in which adherence supports were discussed was randomized, the ordering may nonetheless have inadvertently influenced perspectives about their relative value. The interviews were conducted during the first few months of the COVID-19 pandemic, and provider perspectives may have reflected pandemicrelated changes in clinical practice since the time of the interviews. This study included the perspectives diverse providers across four cities where HIV infection remains disproportionally high among Black and Hispanic/Latinae women. Our findings contribute to the literature by describing barriers and facilitators of each technology-based approach and clarify how, when, and why each approach might be utilized by a provider in clinical practices to improve the care of pregnant and postpartum women with HIV.

\section{Conclusions}

The findings of this study reveal barriers and facilitators of each technology-based approach and clarify how, when, and why each approach might be utilized by a provider in clinical practices to improve the care of pregnant and postpartum women with HIV. Although providers readily identified practical utility of each approach, they cited numerous barriers to use, including the threat of compromising the patientprovider relationship, and facilitators, including perceived accessibility to patients and the opportunity to forge more contact with the multidisciplinary team. The successful implementation of adherence support approaches requires emphasis on the provider-patient relationship, as well as concomitant structural, interpersonal, and intrapersonal difficulties patients balance with adherence to ART. Future research should integrate provider and patient perspectives on the proliferating approaches to HIV adherence support, provide quantitative assessment of factors that inform provider receptivity to various approaches, and broaden to include complementary approaches to improving outcomes for chronic conditions that often co-occur for people with HIV [23]. 


\section{Abbreviations}

APP: advanced practice provider

ART: antiretroviral therapy

CFIR: Consolidated Framework for Implementation Research

HIV: Human Immunodeficiency Virus

MMRL: Mixed Methods Research Lab

PrEP: pre-exposure prophylaxis

$\mathrm{RN}$ : registered nurse

\section{Declarations}

\section{Ethics approval and consent to participate}

The University of Pennsylvania Institutional Review Board approved the study (protocol number: 842757), and written informed consent was obtained from all study participants.

\section{Consent for publication}

not applicable

\section{Availability of data and materials}

The datasets used and/or analyzed during the current study are available from the corresponding author on reasonable request.

\section{Competing interests}

RKS is the recipient of a Gilead Investigator Sponsored Research award, managed by MedStar Health Research Institute. All other authors declare that they have no competing interests or relevant financial interests to disclose.

\section{Funding}

Research reported in this publication was supported by the National Institute on Minority Health and Health Disparities of the National Institutes of Health $(\mathrm{NIH})$ under Award Number R01MD013558 (parent grant) and by an administrative supplement from the Office of Research on Women's Health R01MD013558-02S1. Disclaimer: The content is solely the responsibility of the authors and does not necessarily represent the official views of the $\mathrm{NIH}$. 


\section{Authors' contributions}

Conceptualization: FMM, HS, RN, SR, SS; Methodology: FMM, HS, RN, SR, WRS, ZB; Data curation: RN, ZB; Project Administration: HN, RN, ZB; Formal analysis and investigation: FMM, HS, SR, RN, ZB; Funding acquisition: FMM, HS; Validation: RKS, AIR, ANS; Supervision: FMM; Writing - original draft preparation: SR; All authors contributed reviewed and edited manuscript drafts including the final draft of the manuscript.

\section{Acknowledgements}

not applicable

\section{References}

1. Momplaisir FM, Storm DS, Nkwihoreze H, Jayeola O, Jemmott JB. Improving postpartum retention in care for women living with HIV in the United States. AIDS. 2018 Jan 14;32(2):133-142. doi: 10.1097/QAD.0000000000001707. PMID: 29194122; PMCID: PMC5757672.

2. Phillips, T. K., Bonnet, K., Myer, L., Buthelezi, S., Rini, Z., Bassett, J. et al. (2019). Acceptability of Interventions to Improve Engagement in HIV Care Among Pregnant and Postpartum Women at Two Urban Clinics in South Africa. Matern Child Health J. 2019 Sep;23(9):1260-1270. doi: 10.1007/s10995-019-02766-9. PMID: 31218606; PMCID: PMC7185033.

3. Mayer JE, Fontelo P. Meta-analysis on the effect of text message reminders for HIV-related compliance. AIDS Care. 2017 Apr;29(4):409-417. doi: 10.1080/09540121.2016.1214674. Epub 2016 Aug 1. PMID: 27477580; PMCID: PMC5480218.

4. McDonald HP, Garg AX, Haynes RB. Interventions to enhance patient adherence to medication prescriptions: scientific review. JAMA. 2002 Dec 11;288(22):2868-79. doi:

10.1001/jama.288.22.2868. Erratum in: JAMA. 2003 Jun 25;289(24):3242. PMID: 12472329.

5. Reese PP, Bloom RD, Trofe-Clark J, Mussell A, Leidy D, Levsky S, et al. Automated Reminders and Physician Notification to Promote Immunosuppression Adherence Among Kidney Transplant Recipients: A Randomized Trial. Am J Kidney Dis. 2017 Mar;69(3):400-409. doi: 10.1053/j.ajkd.2016.10.017. Epub 2016 Dec 7. PMID: 27940063.

6. Waltz E. Drugs go wireless. Nat Biotechnol. 2016 Jan;34(1):15-8. doi: 10.1038/nbt.3446. PMID: 26744969.

7. Damschroder LJ, Aron DC, Keith RE, Kirsh SR, Alexander JA, Lowery JC. Fostering implementation of health services research findings into practice: a consolidated framework for advancing implementation science. Implement Sci. 2009 Aug 7;4:50. doi: 10.1186/1748-5908-4-50. PMID: 19664226; PMCID: PMC2736161.

8. Keith RE, Crosson JC, O'Malley AS, Cromp D, Taylor EF. Using the Consolidated Framework for Implementation Research (CFIR) to produce actionable findings: a rapid-cycle evaluation approach to 
improving implementation. Implement Sci. 2017 Feb 10;12(1):15. doi: 10.1186/s13012-017-0550-7. PMID: 28187747; PMCID: PMC5303301.

9. Flickinger TE, Saha S, Moore RD, Beach MC. Higher quality communication and relationships are associated with improved patient engagement in HIV care. J Acquir Immune Defic Syndr. 2013 Jul 1;63(3):362-6. doi: 10.1097/QAI.0b013e318295b86a. PMID: 23591637; PMCID: PMC3752691.

10. Schneider J, Kaplan SH, Greenfield S, Li W, Wilson IB. Better physician-patient relationships are associated with higher reported adherence to antiretroviral therapy in patients with HIV infection. $J$ Gen Intern Med. 2004 Nov;19(11):1096-103. doi: 10.1111/j.1525-1497.2004.30418.x. PMID: 15566438; PMCID: PMC1494791.

11. Beach MC, Duggan PS, Moore RD. Is patients' preferred involvement in health decisions related to outcomes for patients with HIV? J Gen Intern Med. 2007 Aug;22(8):1119-24. doi: 10.1007/s11606007-0241-1. Epub 2007 May 19. PMID: 17514382; PMCID: PMC2305727.

12. Murray, M.C.M., O'Shaughnessy, S., Smillie, K. et al. Health care providers' perspectives on a weekly text-messaging intervention to engage HIV-positive persons in care (WelTel BC1). AIDS Behav. 2015 Oct;19(10):1875-87. doi: 10.1007/s10461-015-1151-6. PMID: 26297567.

13. Abel E, Painter L. Factors that influence adherence to HIV medications: perceptions of women and health care providers. J Assoc Nurses AIDS Care. 2003 Jul-Aug;14(4):61-9. doi: 10.1177/1055329003252879. PMID: 12953613.

14. Rivero-Méndez M, Dawson-Rose CS, Solís-Báez SS. A Qualitative Study of Providers' Perception of Adherence of Women Living with HIV/AIDS in Puerto Rico. Qual Rep. 2010 Mar 1;15(2):232-251. PMID: 21243076; PMCID: PMC3020787.

15. A Peer-Led Intervention to Improve Postpartum Retention in HIV Care available at: https://www.clinicaltrials.gov/ct2/show/NCT04168008? term=momplaisir\&recrs=ab\&cond=hiv\&draw=2\&rank=1. Last accessed 14 April 2021.

16. Bourgois P, Holmes SM, Sue K, Quesada J. Structural Vulnerability: Operationalizing the Concept to Address Health Disparities in Clinical Care. Acad Med. 2017 Mar;92(3):299-307. doi: 10.1097/ACM.0000000000001294. PMID: 27415443; PMCID: PMC5233668.

17. Edhlund B, McDougall A. NVivo 12 essentials. Form \& Kunskap AB 2019.

18. Webel AR, Cuca Y, Okonsky JG, Asher AK, Kaihura A, Salata RA. The impact of social context on selfmanagement in women living with HIV. Soc Sci Med. 2013 Jun;87:147-54. doi:

10.1016/j.socscimed.2013.03.037. Epub 2013 Apr 3. PMID: 23631790; PMCID: PMC3656470.

19. de Los Rios P, Okoli C, Punekar Y, Allan B, Muchenje M, Castellanos E, et al. Prevalence, determinants, and impact of suboptimal adherence to HIV medication in 25 countries. Prev Med. 2020 Oct;139:106182. doi: 10.1016/j.ypmed.2020.106182. Epub 2020 Jun 25. PMID: 32593732.

20. Fagbami O, Oluwasanjo A, Fitzpatrick C, Fairchild R, Shin A, Donato A. Factors Supporting and Inhibiting Adherence to HIV Medication Regimen in Women: A Qualitative Analysis of Patient Interviews. Open AIDS J. 2015 May 15;9:45-50. doi: 10.2174/1874613601509010045. PMID: 26157537; PMCID: PMC4483537. 
21. Simoni, J.M., Huh, D; Frick, P.A., Pearson, C.R., Andrasik, M.P., Dunbar, P.J., et al. Peer support and pager messaging to promote antiretroviral modifying therapy in Seattle: a randomized controlled trial. J Acquir Immune Defic Syndr. 2009 Dec 1;52(4):465-473. doi: 10.1097/qai.0b013e3181b9300c. PMID: 19911481; PMCID: PMC2795576.

22. Yehia, B.R., Stewart, L., Momplaisir, F. et al. Barriers and facilitators to patient retention in HIV care. BMC Infect Dis 15, 246 (2015). doi: 10.1186/s12879-015-0990-0. PMID: 26123158 PMCID: PMC4485864

23. Choudhry NK, Isaac T, Lauffenburger JC, Gopalakrishnan C, Lee M, Vachon A, et al. Effect of a Remotely Delivered Tailored Multicomponent Approach to Enhance Medication Taking for Patients With Hyperlipidemia, Hypertension, and Diabetes: The STIC2IT Cluster Randomized Clinical Trial. JAMA Intern Med. 2018 Sep 1;178(9):1182-1189. doi: 10.1001/jamainternmed.2018.3189. PMID: 30083727; PMCID: PMC6142966. 